\title{
(- OPEN ACCESS \\ Long-term effects of compulsory schooling on physical, mental and cognitive ageing: a natural experiment
}

\author{
Emilie Courtin, ${ }^{1}$ Vahe Nafilyan, ${ }^{2}$ Maria Glymour, ${ }^{3}$ Marcel Goldberg, ${ }^{4,5}$ Claudine Berr, ${ }^{6}$ \\ Lisa F Berkman, ${ }^{1}$ Marie Zins, ${ }^{4,5}$ Mauricio Avendano ${ }^{7,8}$
}

\begin{abstract}
- Additional material is published online only. To view please visit the journal online (http://dx.doi.org/10.1136/ jech-2018-211746).

${ }^{1}$ Harvard Center for Population and Development Studies,

Harvard University, Cambridge, Massachusetts, USA

${ }^{2}$ King's Business School, King's College London, London, UK ${ }^{3}$ Department of Epidemiology and Biostatistics, University of California at San Francisco, San Francisco, California, USA ${ }^{4}$ Medical School, Paris Descartes University, Paris, France ${ }^{5}$ Population-based Epidemiologic Cohorts Unit, UMS 011, INSERM, Villejuif, France

${ }^{6}$ Neuropsychiatry: Epidemiological and Clinical Research, U1061, INSERM, Montpellier, France ${ }^{7}$ Department of Global Health and Social Medicine, King's College London, London, UK ${ }^{8}$ Department of Social and Behavioral Sciences, T H Chan School of Public Health, Harvard University, Boston, Massachusetts, USA
\end{abstract}

Correspondence to Dr Emilie Courtin, Harvard Center for Population and Development Studies, Cambridge, MA 02138, USA ecourtin@hsph.harvard.edu

Received 16 October 2018 Revised 12 December 2018 Accepted 14 December 2018 Published Online First 11 January 2019

\section{Check for updates}

(C) Author(s) (or their employer(s)) 2019. Re-use permitted under CC BY-NC. No commercial re-use. See rights and permissions. Published by BMJ.

To cite: Courtin E, Nafilyan $\mathrm{V}_{\text {, }}$ Glymour M, et al. J

Epidemiol Community Health 2019:73:370-376.

\begin{abstract}
Background Longer schooling is associated with better physical, mental and cognitive functioning, but there is controversy as to whether these associations are causal. We examine the long-term health impact of a policy that increased compulsory schooling by 2 years in France for cohorts born on or after January 1953, offering a natural experiment.

Methods Data came from Constances, a randomly selected cohort of the French population assessed for cognition, depressive symptoms and physical functioning at ages 45 and older $(n=18929)$. We use a Regression Discontinuity Design to estimate the impact of increased schooling duration on health. Cognition was measured based on five validated neuropsychological tests and combined into an overall score. The Center for Epidemiological Studies Depression scale was used to assess depressive symptoms levels. Physical functioning was included as finger tapping, hand grip strength and walking speed.
\end{abstract}

Results The reform increased average schooling, particularly among participants from disadvantaged families. Estimates suggest that for men, this reform improved cognitive scores $(\beta=0.15,95 \% \mathrm{Cl} 0.02$ to 0.27 ), but had no impact on physical functioning. Among women, the reform did not increase cognitive scores or physical functioning but led to higher levels of depressive symptoms ( $\beta=1.52,95 \% \mathrm{Cl} 0.32$ to 2.72 ). Results were robust to a range of sensitivity analyses.

Conclusion These findings highlight the need to carefully consider the potential limits of policies that increase the length of compulsory schooling as strategies to improve population health.

\section{INTRODUCTION}

Education is often conceived as one of the social determinants of health amenable to public policy intervention. In Europe and the USA, lower educational attainment is associated with higher rates of mortality ${ }^{1}$ as well as poorer health. ${ }^{2}$ If these associations reflect a causal relationship, education policies offer an important avenue of intervention on social determinants, through mechanisms such as improved occupational and income mobility, better health literacy and increased social capital and particularly among individuals from lower socioeconomic position (SEP). ${ }^{1}$ However, whether policies that increase compulsory schooling improve health is not fully established.
Many countries across the world introduced reforms to increase the number of years children must attend school. Several studies have used these laws as 'natural experiments', with the rationale that increases in education arising from these reforms are uncorrelated with potential confounders such as family characteristics or individual preferences which may bias the association between education and health. ${ }^{1}$ However, there is no consensus on whether increases in schooling translate into improvements in health in later life. Some studies have found that more years of schooling improve cognition, ${ }^{3-5}$ health behaviours, ${ }^{67}$ physical health ${ }^{8}$ and mortality, ${ }^{9-12}$ while others have reported negative or null effects on physical health and biomarkers, ${ }^{13} 14$ mental health ${ }^{1516}$ or mortality. ${ }^{17-19}$

In this study, we estimate the effect of the Berthoin reform, a major schooling law which increased the minimum school leave age by 2 years in 1959 in France. The exogenous sharp increase in school duration enables us to assess the causal effect of schooling duration on health decades later in a large cohort. We make two contributions to the evidence base linking law-mandated increases in schooling to health. First, we examine the effect of the reform on cognitive, mental and physical functioning as compulsory schooling might improve some health dimensions while worsening others. ${ }^{20}$ Second, we explore heterogeneous effects by gender and family background at the time of the reform, two important variables given the differential return on education documented for women and individuals from disadvantaged families. ${ }^{21} 22$

\section{METHODS}

\section{Data}

To measure the health effects of the reform, we use data from the Constances study, a large prospective community-based cohort study started in 2012. ${ }^{23}$ Participants were randomly selected to take part in the study and invited to undergo a 1 day clinical examination at 1 of 22 Health Screening Centres run by the National Health Insurance Agency, which covers $85 \%$ of the French population. At baseline, a range of comprehensive health assessments were carried out by health professionals, and participants were asked to complete questionnaires about their health, behaviours and socioeconomic circumstances. Our original sample comprised 33762 individuals aged 45 years and older. We follow previous research ${ }^{19}$ to choose the bandwidth 
(number of cohorts born before and after the reform) and focus on respondents born 48 months before or after the cut-off for eligibility to the reform $(n=18928)$.

To document the impact of the reform on school leaving age we use the French Labor Force Survey (LFS), a household survey representative of the French population living in private households. We use data on the age at which respondents left full-time education measured in the 2012 wave. We include respondents born within 48 months of the reform, which includes 72133 individuals.

\section{Outcomes}

In Constances, mental health was measured using the 20-item version of the Centre for Epidemiologic Studies Depression scale (CES-D), ${ }^{24}$ a validated depressive symptoms scale. Higher scores indicate higher levels of depressive symptoms and a cut-off of 16 for men and 20 for women was used to define elevated levels of depressive symptoms. ${ }^{25}$

Cognitive function was assessed by trained neuropsychologists using five tests. ${ }^{26}$ The Mini-Mental State Examination (MMSE) is a general test of cognitive function consisting of 30 questions assessing five areas of cognition: orientation, registration, attention and calculation, recall and language. The DigitSymbol Substitution Task of the Wechsler adult intelligence scale IV assesses psychomotor speed. The respondents were presented with nine digit-symbol pairs, followed by a list of numerical digits. They were asked to write the corresponding symbol under each digit as fast as possible. We retain the number of symbols correctly associated in $90 \mathrm{~s}^{27}$ The Free and Cued Selective Reminding Test (FCSRT) measures verbal episodic memory. Respondents were first asked to read and memorise 16 words, then asked to recall as many words as possible in $2 \mathrm{~min}$. The neuropsychologist provided a cue for each word that has not been retrieved. For this study, we include the FCSRT free immediate recall score. Finally, two verbal fluency tasks were included to assess language abilities: number of words related to the 'animals' category named in $1 \mathrm{~min}$ for the semantic fluency task and number of words starting with the letter ' $R$ ' named in $1 \mathrm{~min}$ for the phonemic fluency task. As the scale of each individual cognitive test differs, each score is converted to a z-score by subtracting the mean and dividing by the SD. A global cognitive score is obtained by summing the standardised tests. High cognitive performance is defined as the top quartile of the global score's distribution.

Physical functioning is assessed based on three objective health measures. Hand grip strength was assessed using a handheld dynamometer. Participants were asked to sit and squeeze the dynamometer for a few seconds with their dominant hand. The exercise was repeated three times and grip strength was determined as the average of the three results. Finger tapping, a measure of motor performance, was assessed by the number of taps respondents could do with the index finger of their dominant hand for $15 \mathrm{~s}$. Walking speed was measured as the time taken by respondents to walk $3 \mathrm{~m}$ at a rapid pace. For each physical health outcome, high levels of physical functioning are defined based on the top quartile of the distribution.

\section{Years of schooling and completed education}

Schooling is measured as the age at which respondents left fulltime schooling (in the French LFS) and the highest level of education completed (in the Constances data). Educational attainment in Constances is reclassified into four categories: primary education or less, lower secondary education, upper secondary education and tertiary education.

\section{Parental socioeconomic position}

Parental SEP during the respondent's adolescence is based on the French classification of professions and socioprofessional categories. It is recategorised into high (managerial, professional occupations), intermediate (trade and services related occupations) and low parental SEP (manual occupations).

\section{Analysis design}

We implement a Regression Discontinuity Design (RDD), a quasi-experimental approach used to isolate the causal effect of an exposure using observational data. ${ }^{28}$ It aims to address unmeasured confounding and reverse causality by exploiting the discontinuity in schooling duration generated by the reform across otherwise similar cohorts. The reform raised the minimum school leaving age for all children born after 1 January 1953 from 14 to 16 years. Our approach classifies respondents born after this cut-off date as the eligible group, while respondents born prior to the cut-off were classified as the ineligible comparison group. RDD compares outcomes between these groups, appropriately accounting for secular trends using local linear regression.

Because some respondents would have stayed at school beyond the age of 14 in the absence of the reform, we implement a fuzzy RDD and estimate an intent-to-treat effect. Our estimates do not capture the impact of additional schooling per se, but the impact of eligibility to a policy that requires students to stay until age 16 at school. Our main model specification is as follows:

$$
\text { Health }_{i c t}=\gamma_{0}+\gamma_{1} D_{i c}+f\left(R_{i c}\right)+\gamma_{2} X_{i c t}+u_{i c t}
$$

where Health ${ }_{\text {ict }}$ is a health outcome measure for individual $i$ from birth cohort $c$ at time $t$; $D_{\text {ic }}$ is a binary variable taking the value of 1 if an individual was born after the cut-off date, and of 0 if the individual was born prior to this date; $R_{\mathrm{ic}}$ is an individual's birth cohort relative to 1 January 1953 measured in months, which aims to capture secular trends and $X_{\text {ict }}$ is a vector of individual characteristics: age, age squared, gender and month of birth. The coefficient $\gamma_{1}$ denotes the health effect of being eligible to the reform. Using local linear regression we model birth cohort effects as a piecewise linear function, with different slopes on each side of the cut-off date.

We explore heterogeneous effects by first stratifying our models by gender and parental SEP and then interacting the reform dummy with these variables. Ordinary least squares regressions are used to obtain coefficients and 95\% CIs for continuous scores and logistic regressions for OR and 95\% CIs for dichotomous outcomes. SEs are clustered at the month of birth level, as recommended when the variable which determines eligibility is discrete. ${ }^{29}$ To ensure that the functional form is correctly specified, we also estimate models with a cubic term for age. Additional models using triangular kernel weights are estimated to test whether our findings are robust to giving more weights to observations which are closer to the cut-off for eligibility. All analyses were carried out using Stata V.14.

\section{RESULTS}

Table 1 presents basic characteristics for respondents in our analytical sample $(\mathrm{n}=18929) .9635$ respondents (mean age $=63.68$ years) were born up to 48 months before the policy and constitute our ineligible group, while 9293 respondents (mean age $=59.72$ years) were born up to 48 months after the policy and compose our eligible group. Pre-reform characteristics are similar across the two groups. Additional descriptive statistics are provided in online supplementary appendix table 1. 
Table 1 Sample characteristics by eligibility status in the 2012 Constances study $(n=18929)$

\begin{tabular}{|c|c|c|c|}
\hline & Percentage* & & \\
\hline & $\begin{array}{l}\text { Ineligible (born before the } 1 \\
\text { January 1953) }(n=9635)\end{array}$ & $\begin{array}{l}\text { Eligible (born after the } 1 \\
\text { January 1953) }(n=9293)\end{array}$ & Difference ( $p$ value) \\
\hline Mean age (SD) & $63.68(1.65)$ & $59.72(1.65)$ & $<0.001$ \\
\hline Gender & & & 0.10 \\
\hline Male & 48.75 & 48.01 & \\
\hline Female & 51.25 & 51.99 & \\
\hline Father's SEP during adolescence & & & 0.19 \\
\hline High SEP & 14.86 & 15.47 & \\
\hline Intermediate SEP & 38.99 & 38.77 & \\
\hline Low SEP & 46.14 & 45.75 & \\
\hline Father's region of origin & & & 0.09 \\
\hline France (mainland and overseas territories and departments) & 84.65 & 84.70 & \\
\hline Europe & 8.40 & 7.94 & \\
\hline Northern Africa & 3.87 & 4.50 & \\
\hline Other & 3.08 & 2.86 & \\
\hline Educational attainment & & & 0.17 \\
\hline Primary & 3.35 & 3.24 & \\
\hline Secondary & 53.96 & 53.99 & \\
\hline Tertiary & 42.70 & 42.77 & \\
\hline Respondent's SEP & & & 0.12 \\
\hline High SEP & 31.82 & 28.35 & \\
\hline Intermediate SEP & 57.82 & 60.39 & \\
\hline Low SEP & 10.36 & 11.26 & \\
\hline
\end{tabular}

*Percentages unless otherwise indicated. Only respondents born within 48 months of the cut-off are included in our sample.

SEP, socioeconomic position.

Online supplementary appendix figure 1 shows a strong educational gradient in mental and cognitive health in our sample, with higher educated respondents enjoying higher cognition and lower levels of depressive symptoms. A less pronounced association was found for finger tapping. There is no apparent relationship between educational attainment and grip strength or gait speed in our sample.

Figure 1 displays the effect of eligibility to the reform on the proportion of respondents who left school after the age of 16 by gender and birth cohort in the French LFS. There is a clear discontinuity - an increase larger than expected based on the modelled trend-at the time of the reform. Table 2 indicates that the reform increased the time spent at school by 2.76 months for men (95\% CI 1.45 to 4.29 ) and by 2.88 months for women (95\% CI 1.40 to 4.36 ). It was also associated with higher odds of leaving school after the age of 16 for both men and women. Supplementary analyses (online supplementary appendix table 2) show that the effect is concentrated among participants from disadvantaged backgrounds ( $p$ value for interaction term $<0.001$ ).

Figure 2 presents the effect of eligibility to the reform on each health outcome by gender and birth cohort. There is an apparent discontinuity in cognitive scores for men and depressive symptoms for women for the 1953 cohort, suggesting that the reform may have increased cognition in men but also depressive symptoms scores among women. Table 3 presents local regression estimates of the effect of the reform on health. Males required to stay at school longer had higher cognitive scores $(\beta=0.15$, $95 \%$ CI 0.06 to 0.24 ) and higher odds of being in the top quartile of cognitive performance $(\mathrm{OR}=1.81,95 \% \mathrm{CI} 1.26$ to 2.66 ) compared with those who were permitted to leave school at age
14. Results by individual cognitive score (online supplementary appendix table 3) show that this effect was driven by higher scores on the MMSE and memory test. Eligibility to the reform had no effect on depressive scores or physical functioning among men.

Among women, there are no significant effects of eligibility on cognition overall or on specific cognitive tests (online supplementary appendix table 3 ). The $\mathrm{p}$ value for the interaction term between eligibility to the policy and gender is significant $(p=0.03$, online supplementary appendix table 4$)$. However, women eligible to the reform scored 1.52 points $(95 \%$ CI 0.33 to 2.71) higher on the CES-D depression scale and had higher odds of elevated depressive symptoms $(\mathrm{OR}=1.27,95 \% \mathrm{CI} 1.05$ to 1.54$)$. We find no effect of the reform on women's physical functioning.

Supplementary analyses stratified by parental SEP (online supplementary appendix table 5) indicate that these effects are concentrated among respondents from disadvantaged families although the interaction term between eligibility to the reform and low parental SEP is not significant either for cognition $(p=0.12)$ or depressive symptoms $(p=0.18$, online supplementary appendix table 4). Additional analyses on intermediate socioeconomic outcomes indicate that the reform did not translate into higher qualifications or wages for either gender but was associated with higher odds of being in employment in 2012 among men (online supplementary appendix table 6). The reform was also not associated among women with marital status or number of children (online supplementary appendix table 7).

We conducted several sensitivity analyses to check the robustness of our findings. ${ }^{30}$ First, our results on cognition and depressive symptoms are robust to the inclusion of a cubic term for age 


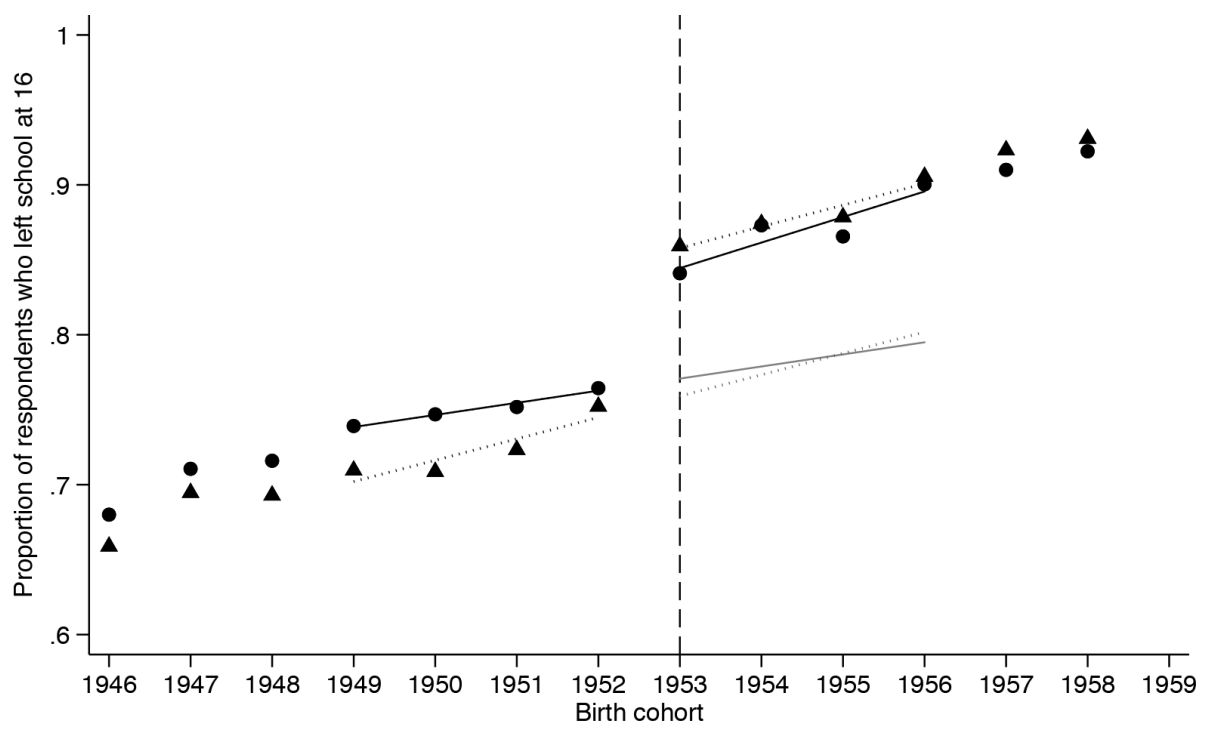

$$
\begin{array}{lll}
\text { - Monthly average - Men } & & \text { Trend - Men } \\
\text { A Monthly average - Women } & \ldots \ldots \ldots \ldots \ldots & \text { Trend - Women }
\end{array}
$$

Figure 1 Effect of eligibility to the 1959 Berthoin reform on the proportion of respondents who left school after 16 by gender in the 2012 French Labor Force Survey ( $n=72133$ ), Birth cohorts 1946-1959. The dots and triangles show the average school leaving age, respectively, for men and women and for each birth cohort. The dashed line represents the cut-off for eligibility to the reform (1 January 1953). The fitted lines represent the linear trends for our analytical sample: respondents born up to 48 months before or after the reform, separately for men (black lines) and women (dotted lines). The grey fitted lines show the predicted school leaving age in the absence of the reform.

(online supplementary appendix table 8) and to an alternative estimation with triangular kernel weights (online supplementary appendix table 9). Second, to confirm that our estimates are driven by the reform and not by secular trends, we estimate the effect of 'placebo reforms' for years in which the reform did not take place (online supplementary appendix figure 2). Analyses revealed no evidence of other discontinuities for cognition among men and for depressive symptoms among women. Third, we experiment with different bandwidths, ranging from 12 to 72 months. Results presented in online supplementary appendix figure 3 indicate that our estimates are also robust to different bandwidth sizes.

\section{DISCUSSION}

We leverage the discontinuity in schooling duration induced by a major French reform to estimate the long-term effects of schooling on adult health. Our results offer a complex picture: while men who stayed longer in school as a result of the reform had better cognitive function in older age, women eligible to reform did not show gains in cognitive function and instead displayed higher levels of depressive symptoms in midlife.

\section{Effects on cognition}

Our findings are consistent with previous evidence of long-term positive effects of schooling reforms on memory scores, ${ }^{34}$ in particular among men. ${ }^{31}$ These findings suggest that increased schooling may increase cognitive reserve and thus postpone the manifestation of cognitive decline in later life. ${ }^{32}$ These effects were confined to men, which might be in part due to the relatively young age of respondents in our sample: women have lower incidence of dementia before 75 and are less affected in early old age by vascular midlife risk factors than men. ${ }^{33}$

\section{Effects on mental health}

Eligibility to the reform was associated with higher levels of depressive symptoms among women. We found a clear association between educational attainment and depressive symptoms

Table 2 Effect of eligibility to the 1959 Berthoin reform on average school leaving age and odds of leaving school after the age of 16 , by gender and parental SEP during adolescence in the 2012 French Labor Force Survey $(n=72133)$

\begin{tabular}{|c|c|c|c|c|c|c|c|c|}
\hline & \multicolumn{4}{|l|}{ Men } & \multicolumn{4}{|l|}{ Women } \\
\hline & $\beta$ & $95 \% \mathrm{Cl}$ & OR & $95 \% \mathrm{Cl}$ & $\beta$ & $95 \% \mathrm{Cl}$ & OR & $95 \% \mathrm{Cl}$ \\
\hline All respondents & 0.24 & 0.12 to 0.36 & 1.49 & 1.30 to 1.70 & 0.24 & 0.12 to 0.36 & 1.93 & 1.69 to 2.21 \\
\hline High parental SEP & -0.03 & -0.52 to 0.46 & 0.84 & 0.27 to 2.62 & -0.222 & -0.63 to 0.18 & 1.012 & 0.33 to 3.11 \\
\hline Intermediate parental SEP & 0.03 & -0.23 to 0.29 & 1.06 & 0.80 to 1.39 & 0.098 & -0.07 to 0.27 & 1.58 & 1.25 to 1.99 \\
\hline Low parental SEP & 0.33 & 0.19 to 0.47 & 1.69 & 1.47 to 1.96 & 0.353 & 0.19 to 0.52 & 2.05 & 1.76 to 2.39 \\
\hline
\end{tabular}

The ordinary least square estimates measure the effect of the reform on average school leaving age while ORs measure the effect of the reform on the odds of leaving school after the age of 16. All models control for age, age squared, month of birth, birth cohort relative to the cut-off point, interacted with the treatment. SEs are clustered at the month of birth level. The bandwidth is fixed at 48 months.

SEP, socioeconomic position. 


\section{A Standardized cognitive score}

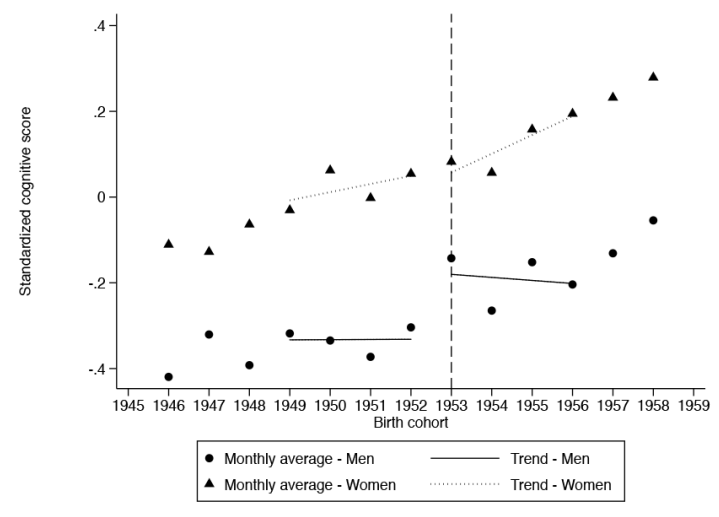

\section{B CES-D depressive symptoms score}

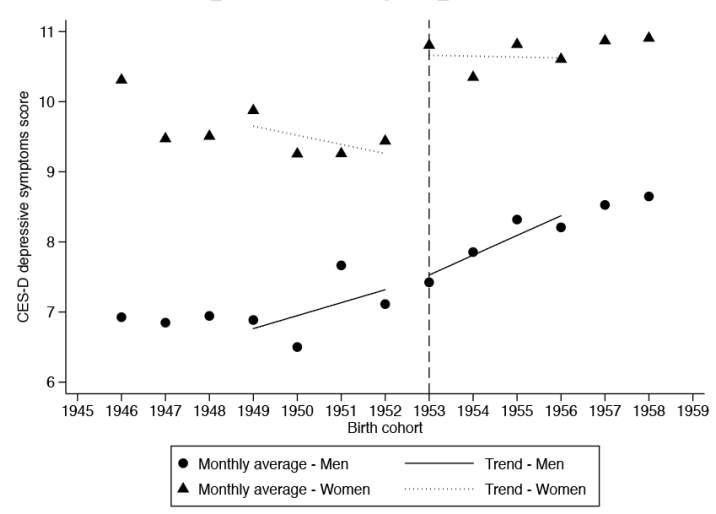

\section{Physical functioning measures}
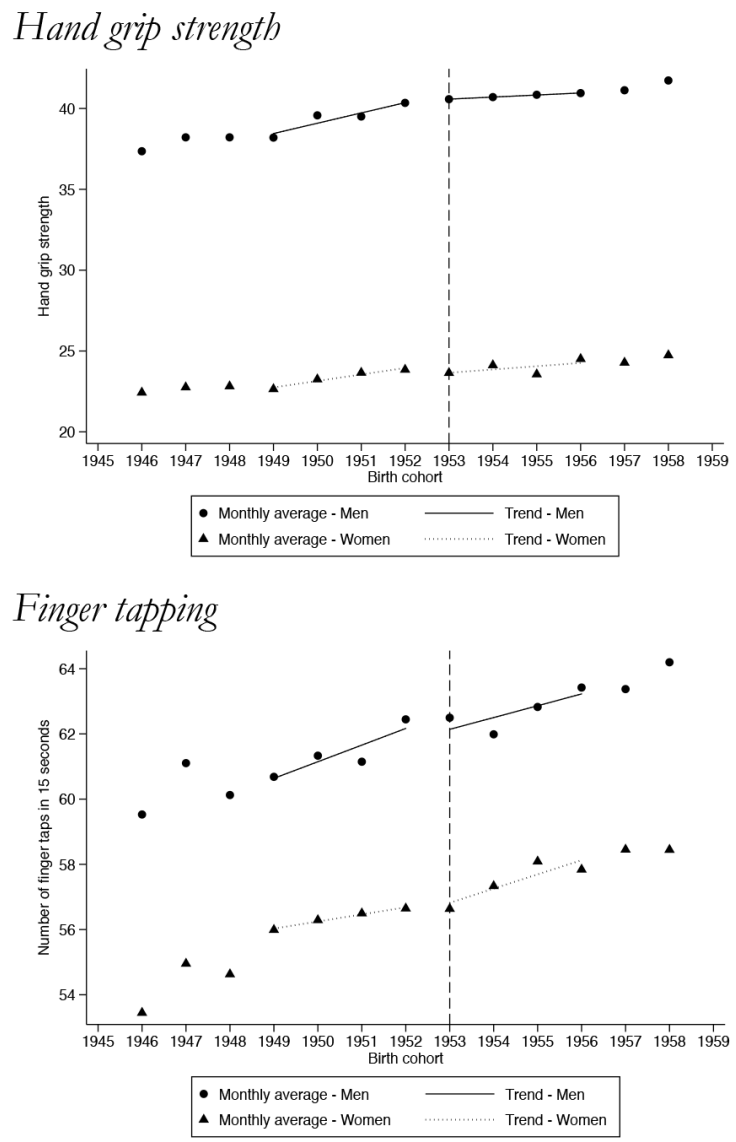

Walking speed

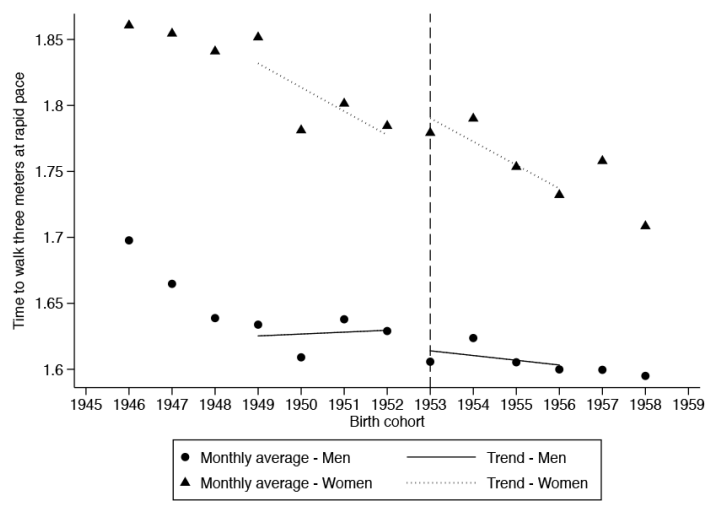

Figure 2 Effect of eligibility to the 1959 Berthoin reform on health outcomes by gender in the 2012 Constances Study ( $\mathrm{n}=33$ 762), Birth Cohorts 1946-1959. The dots and triangles show the average school leaving age, respectively, for men and women and for each birth cohort. The dashed line represents the cut-off for eligibility to the reform (1 January 1953). The fitted lines represent the linear trends for our analytical sample: respondents born up to 48 months before or after the reform, separately for men (black lines) and women (dotted lines). CES-D, Center for Epidemiologic Studies Depressive Symptoms Scale.

in our sample for both genders. ${ }^{34}$ However, the sign reversed for women once we implemented an RD design exploiting the change in schooling duration. This result echoes findings from recent quasi-experimental studies in Sweden, Great Britain and Turkey ${ }^{15} 1635$ reporting negative effects of schooling on mental health and emotional well-being. A recent review concluded that evidence of a positive effect of schooling on women's health is overall weaker than for men. ${ }^{22}$
There are several possible explanations for these results. Education is hypothesised to influence health partly by enhancing access to health-promoting resources such as health literacy, self-efficacy, social networks and better jobs and earnings. ${ }^{1}$ Available evidence suggests that the French reform-contrary to other schooling laws in the USA and Western Europe-did not lead to substantive improvements in qualifications or earnings. ${ }^{36}$ Our analyses partly confirm this pattern: longer schooling 
Table 3 Effect of eligibility to the 1959 Berthoin reform on health outcomes by gender in the 2012 Constances study $(n=18929)$

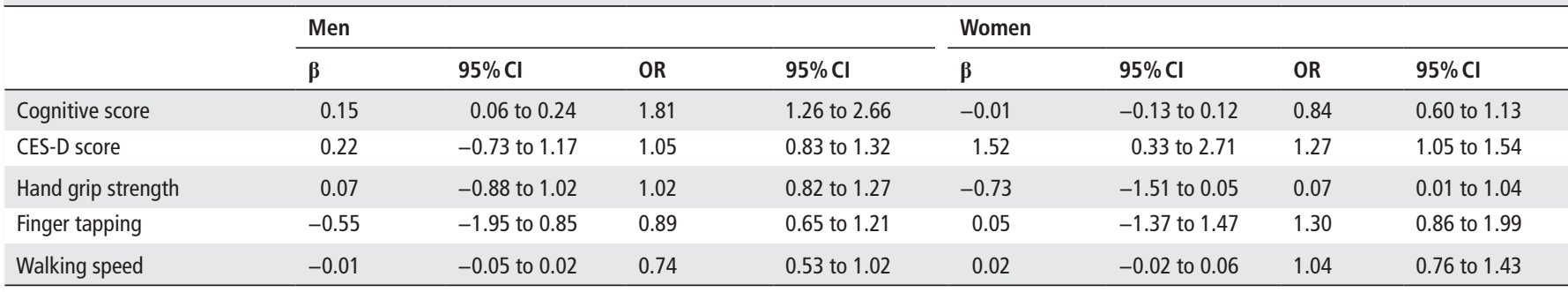

ORs measure the odds of being in the top quartile of cognitive and physical functioning and of reporting elevated depressive symptoms based on the CES-D recommended cut-off. All models control for age, age squared, month of birth, birth cohort relative to the cut-off point, interacted with the treatment. Standard errors are clustered at the month of birth level. The bandwidth is fixed at 48 months.

CES-D, Centre for Epidemiologic Studies Depression score.

did not translate into higher qualifications or wages for either gender but was associated with higher odds of being in employment in 2012 among men. For women, the additional years of schooling were not associated with an upgrading of their position in the labour market, potentially creating a job-education mismatch detrimental for mental health. ${ }^{37}$ The discrepancy between the expectations created by the reform and the actual long-term benefits might have been particularly harmful for women's mental health as research suggests that women have smaller economic returns on education. ${ }^{38}$ A second hypothesis is that the health effects of education for women operated partly through the marriage market and not exclusively through employment and wages. ${ }^{22} 39$ However, the reform did not exert any effects through this pathway as eligibility was not associated with women's marital status or number of children.

\section{Effects on physical functioning}

Consistent with our findings for physical functioning, previous studies have reported weak or inconsistent effects of schooling laws on physical health. ${ }^{40}$ There are three possible interpretations. First, we may not have enough power to detect the effect of the reform on physical health: the CIs for these estimates are wide and include substantial benefits as well as harms as plausible effects. Second, our sample was relatively young and these measures may not discriminate subtle differences in physical functioning in younger age. A third possible interpretation is that the commonly observed association between education and functioning may be partly driven by selection. A potential implication would be that increasing compulsory schooling may not be an effective policy to improve physical health. A recent theoretical framework linking human capital, schooling and health identified skills formation as a critical pathway. ${ }^{22}$ Our results indicate that degree attainment and skill formation-which were not impacted by the Berthoin reform-might be more important for health than the amount of time spent in school.

\section{Strengths and limitations}

Major strengths of our study include the use of a quasi-experimental design in a large population-based cohort, as well as an extensive battery of objective health measures. RDD is a powerful tool to estimate causal effects of policies for which eligibility is based on a clearly defined threshold or time point. ${ }^{28} \mathrm{~A}$ limitation is that our data are cross-sectional, so we were unable to examine longitudinal trajectories. Reverse causality, however, is not a concern in our study because the reform affected cohorts decades before health measures were taken. In addition, if exposure to the policy is 'as good as' random, using cross-sectional data should not compromise estimates of the impact of the policy on health outcomes in later life.
Taken together, our findings provide a mixed picture of the long-term health effects of a policy that increased compulsory schooling. Decades after implementation, the Berthoin reform led to better cognitive outcomes among men, but also to increased rates of depressive symptoms among women. The reform had no measurable impact on physical functioning. Our results do not suggest that education is not beneficial for health but indicate that policies focused on increasing the quantity of schooling and not its quality, for example, might not be the best tool to improve population health.

\section{What is already known on this subject}

- Education is a social determinant of health particularly amenable to public policy reforms.

- Observational studies have suggested that higher education is associated with better health but whether policies that increase schooling duration can also improve health is unclear.

\section{What this study adds}

- Our findings provide new quasi-experimental evidence on the long-term effects of compulsory schooling on a range of adult clinical outcomes.

- An increase in compulsory schooling was associated with large increases in cognition among men and also with increased depressive symptoms among women.

- These results highlight the need to consider the potential trade-offs of schooling laws as tools to improve population health.

Acknowledgements The authors are very grateful to Celine Ribet for her help with data access and management. The authors thank the 'Caisse Nationale d'Assurance Maladie des Travailleurs Salaries' (CNAMTS) and the 'Centres d'Examen de Sante' of the French Social Security which are collecting a large part of the data as well as the 'Caisse Nationale d'Assurance Vieillesse', CinSearch, Asqualab and Eurocell in charge of data quality control.

Contributors EC conceptualised and designed the study, carried out the analyses and drafted the manuscript. VN contributed to the design and analyses, reviewed and revised the manuscript. MA, MMG, MG , CB, LFB and MZ critically reviewed the results of the analyses and reviewed and revised the manuscript. EC is guarantor.

Funding The Constances Cohort Study was supported and funded by the Caisse Nationale d'Assurance Maladie des Travailleurs salaries (CNAMTS). The Constances Cohort Study is an 'Infrastructure Nationale en Biologie et Sante' and benefits from a grant from ANR (ANR-11-INBS-0002). Constances is also partly funded by MSD, AstraZeneca and Lundbeck. This work was supported by the European Union's Horizon 2020 Research and Innovation Programme (Lifepath—grant number 633666). EC and MA are also supported by the Horizon2020 Mindmap project 
(667661). MA is supported by a National Institute on Aging grant (R01AG040248). VN acknowledges financial support from the Economic and Social Research Council (ESRC-KISS DTC).

Disclaimer The study does not necessarily reflect the commission's views and in no way anticipates the Commission's future policy in the area. The funding source did not have a role in the design and conduct of the study, the collection, management, analysis and interpretation of the data or the preparation, approval or decision to submit the manuscript.

Competing interests None declared.

Patient consent Not required.

Ethics approval The Constances cohort received ethical approval from the French National Data Protection Authority (authorisation no. 910486) and the Institutional Review Board of the National Institute for Medical Research (authorisation no. 01-011). No further ethical approval was sought for this study. All participants gave informed consent to participate.

Provenance and peer review Not commissioned; externally peer reviewed.

Data sharing statement The Constances cohort is available for registered users and on approval of a research project by the scientific board at http://www. constances.fr/index_EN.php.

Open access This is an open access article distributed in accordance with the Creative Commons Attribution Non Commercial (CC BY-NC 4.0) license, which permits others to distribute, remix, adapt, build upon this work non-commercially, and license their derivative works on different terms, provided the original work is properly cited, appropriate credit is given, any changes made indicated, and the use is non-commercial. See: http://creativecommons.org/licenses/by-nc/4.0/.

\section{REFERENCES}

1 Glymour M, Avendano M, Kawachi I. In: Berkman LF, Kawachi I, Glymour M, eds. Socioeconomic status and health, in social epidemiology. 2nd edn. New York: Oxford University Press, 2014:17-62.

2 Wilson RS, Hebert LE, Scherr PA, et al. Educational attainment and cognitive decline in old age. Neurology 2009;72:460-5.

3 Glymour MM, Kawachi I, Jencks CS, et al. Does childhood schooling affect old age memory or mental status? Using state schooling laws as natural experiments. J Epidemiol Community Health 2008:62:532-7.

4 Banks J, Mazzonna F. The effect of education on old age cognitive abilities. Econ. J 2012;122:418-48.

5 Nguyen TT, Tchetgen Tchetgen EJ, Kawachi I, et al. Instrumental variable approaches to identifying the causal effect of educational attainment on dementia risk. Ann Epidemiol 2016;26:71-6.

6 Brunello G, Fort M, Schneeweis N, et al. The causal effect of education on health: what is the role of health behaviors? Health Econ 2016;25:314-36.

7 Silles M. The causal effect of schooling on smoking behavior. Econ Educ Rev 2015:48:102-16.

8 Oreopoulos P. Estimating average and local average treatment effects of education when compulsory schooling laws really matter. Am Econ Rev 2006;96:152-75.

9 Lleras-Muney A. The relationship between education and adult mortality in the United States. Rev Econ Stud 2005;72:189-221.

10 Glied S, Lleras-Muney A. Technological innovation and inequality in health. Demography 2008;45:741-61.

11 Davies NM, Dickson M, Davey Smith G, et al. The causal effects of education on health outcomes in the UK Biobank. Nat Hum Behav 2018:2:117-25.

12 Gathmann C, Jürges H, Reinhold S. Compulsory schooling reforms, education and mortality in twentieth century Europe. Soc Sci Med 2015;127:74-82.

13 Adams SJ. Educational attainment and health: evidence from a sample of older adults. Educ Econ 2002;10:97-109.
14 Barcellos S, Carvalho LS, Turley P. Distributional effects of education on health. SSRN Electronic Journal 2018

15 Lager A, Seblova D, Falkstedt D, et al. Cognitive and emotional outcomes after prolonged education: a quasi-experiment on 320182 Swedish boys. Int J Epidemiol 2017;46:1-9.

16 Dursun B, Cesur R. Transforming lives: the impact of compulsory schooling on hope and happiness. J Popul Econ 2016;29:911-56.

17 Clark D, Royer $\mathrm{H}$. The effect of education on adult mortality and health: evidence from Britain. Am Econ Rev 2013;103:2087-120.

18 Lager AC, Torssander J. Causal effect of education on mortality in a quasi-experiment on 1.2 million Swedes. Proc Natl Acad Sci U S A 2012;109:8461-6.

19 Albouy V, Lequien L. Does compulsory education lower mortality? J Health Econ 2009:28:155-68.

20 Hamad R, Elser H, Tran DC, et al. How and why studies disagree about the effects of education on health: A systematic review and meta-analysis of studies of compulsory schooling laws. Soc Sci Med 2018;212:168-78.

21 Brunello G, Fort M, Weber G. Changes in compulsory schooling, education and the distribution of wages in Europe. Econ J 2009;119:516-39.

22 Galama TJ, Lleras-Muney A, van Kippersluis H. The effect of education on health and mortality: a review of experimental and quasi-experimental evidence. Boston, MA National Bureau of Economic Research, 2018.

23 Zins $M$, Goldberg $M$. The French CONSTANCES population-based cohort: design, inclusion and follow-up. Eur J Epidemiol 2015;30:1317-28.

24 Radloff LS. The CES-D scale. a self-report depression scale for research in the general population. Appl. Psychol. Meas 1977;1:385-401.

25 Morin AJ, Moullec G, Maïano C, et al. Psychometric properties of the center for epidemiologic studies depression scale (CES-D) in French clinical and nonclinical adults. Rev Epidemio/ Sante Publique 2011;59:327-40.

26 Mura T, Amieva H, Goldberg M, et al. Effect size for the main cognitive function determinants in a large cross-sectional study. Eur J Neurol 2016;23:1614-26.

27 Wechsler D. Adult intelligence scale-revised. New York: Psychological Corporation, 1981.

28 Venkataramani AS, Bor J, Jena AB. Regression discontinuity designs in healthcare research. BMJ 2016;352:11216.

29 Lee DS, Card D. Regression discontinuity inference with specification error. J Econom 2008;142:655-74.

30 Moscoe E, Bor J, Bärnighausen T. Regression discontinuity designs are underutilized in medicine, epidemiology, and public health: a review of current and best practice. J Clin Epidemiol 2015;68:132-43.

31 Schneeweis N, Skirbekk V, Winter-Ebmer R. Does education improve cognitive performance four decades after school completion? Demography 2014;51:619-43.

32 Stern Y. Cognitive reserve in ageing and Alzheimer's disease. Lancet Neurol 2012:11:1006-12.

33 Singh-Manoux A, Kivimaki M, Glymour MM, et al. Timing of onset of cognitive decline: results from Whitehall II prospective cohort study. BMJ 2012;344:d7622.

34 Lorant $\mathrm{V}$, Deliège $\mathrm{D}$, Eaton $\mathrm{W}$, et al. Socioeconomic inequalities in depression: a metaanalysis. Am J Epidemiol 2003;157:98-112.

35 Nafilyan V, Avendano M, De Coulon A. Does more education always improve mental health? Evidence from a British compulsory schooling reform. York: University of York, HEDG Working Paper series, 2017.

36 Grenet J. Is extending compulsory schooling alone enough to raise earnings? Evidence from French and British compulsory schooling laws*. Scand J Econ 2013:115:176-210.

37 Bracke P, Pattyn E, von dem Knesebeck O. Overeducation and depressive symptoms: diminishing mental health returns to education. Sociol Health IIIn 2013;35:1242-59.

38 Ross CE, Mirowsky J. Sex differences in the effect of education on depression: resource multiplication or resource substitution? Soc Sci Med 2006:63:1400-13.

39 Fort M, Schneeweis N, Winter-Ebmer R. Is education always reducing fertility? evidence from compulsory schooling reforms. Econ J 2016:126:1823-55.

40 Brunello G, Fabbri D, Fort M. The causal effect of education on body mass: evidence from Europe. J Labor Econ 2013:31:195-223. 